\title{
The Extracts from Allium hookeri induces p53-independent Apoptosis through Mitochondrial Intrinsic Pathways in AGS Human Gastric Carcinoma Cells
}

\section{Gun-He Nam¹, Seung-Je Lee ${ }^{1}$, Ga-Yeon Kim¹, Mi-Ji Jeon ${ }^{1}$, Kyung-Jo Jo ${ }^{1}$, Ye-Seul Park', Sang-Yong Kim² and Young-Min Kim ${ }^{1 *}$}

${ }^{1}$ Department of Biological Sciences and Biotechnology, College of Life Science and Nano Technology, Hannam University, Daejeon 34054, Korea ${ }^{2}$ Department of Food Science \& Bio Technology, Shinansan University, Daehakro Danwon-gu, Ansan-city, Gyenggi-do, Korea

\begin{abstract}
Allium hookeri is a traditional plant to treat inflammatory diseases in India and Myanmar. Allium hookeri has anti-cancer and anti-microbial properties. However, till date, apoptotic mechanisms of Allium hookeri extract (AHE) were not investigated yet. In the present study, we aimed to investigate the apoptotic effects of AHE in AGS human gastric carcinoma cells. We confirmed the anti-proliferative activity and apoptotic effects of AHE by MTT assay and Annexin-V staining. In addition, treatment with AHE reduced the expression level of p-Akt. Akt plays an important role in cancer cell survival, growth, and division. Akt down-regulates apoptosis-mediated proteins, such as antiapoptotic proteins. Moreover, AHE increases expression level of tumor suppressor p53 and pro-apoptotic proteins. We treated LY294002 (inhibitor of Akt) and rapamycin (inhibitor of mTOR), pifitrin- $\alpha$ (p53 inhibitor) to determine the relationship between signal transduction of proteins associated with apoptosis. Taken together, our results indicate that AHE could induce apoptosis in AGS human gastric carcinoma cells.
\end{abstract}

Keywords: Allium hookeri; Apoptosis; Gastric carcinoma cells; Tumor suppressor; Anticancer chemotherapy

\section{Introduction}

Cancer is one of the biggest causes of death worldwide, and the death rate from cancer continues to increase in the developed countries and other countries [1]. Today, every third person suffers from cancer [2]. Among various cancer types, stomach cancer is known to be the most frequent cancer regardless of gender. Recent advances in cancer diagnosis and treatment have emphasized the importance of early screening to increase the survival rate of stomach cancer patients [3]. If cancer is diagnosed early, it will be treated with gastric mucosectomy or surgery using a laparoscope. However, in the case of metastasis to other parts of the body, the patient will be treated with anticancer chemotherapy without becoming an indication for the operation. As a result, stomach cancer patients may experience post-removal dumping syndrome, nutritional deficiency, and anemia during the treatment process, and anticancer chemotherapy may cause misdiagnosis, vomiting, constipation, diarrhea, hypostosis, and bone marrow functions.

In previous research, it has been pointed out that this causes patients with stomach cancer to experience physical and psychological pain, leading thus to reduced quality of life [4]. For that reason, many studies have recently been conducted to develop new physiologically active substances based on the efficacy of various natural substances that are harmless to humans, as the natural extracts can inhibit and regulate the signaling molecules associated with the growth and proliferation of cancer cells [5]. Among such natural products, Allium hookeri, which has a variety of physiological activities, such as anti-inflammatory property, is a vegetable mainly consumed in the Himalayas where it is used for various inflammation-related and cancer diseases. Now that Allium hookeri is brought Korea, there is a growing interest in its ingredients and efficacy [6,7]. It was reported that the anti-inflammatory effect of Allium hookeri prevents cell growth and mutagenesis and induces apoptosis (death of a cell) in cancer cells [8]. Therefore, seeking for a new anticancer substance using such natural materials, research is currently underway on which natural extracts induce apoptosis and thus have anticancer effects [9]. Apoptosis is a very important process, because it shrinks cells, condenses nuclei, and forms cell membrane bubbles due to the programmed cell death, and if the cells do not die properly, mutations of some cells will be promoted with cancer [10].

Apoptosis's pathways are divided into extrinsic pathways and intrinsic pathways, especially in mitochondria, which play an important role in the intrinsic pathways of apoptosis. The method is influenced by the relative ratios of $\mathrm{Bcl}-2$, an anti-apoptotic protein, and Bax and Bak proteins of pro-apoptotic protein [11]. Akt (serine/threonine kinase), one of the regulating proteins of apoptosis intrinsic pathways, regulates cell proliferation, differentiation, and growth, and inhibits Bax and Bak [12]. The mTOR activated by Akt is involved in tumor formation and is regulated in cell growth and proliferation $[13,14]$. In addition, mTOR induces ubiquitation of p53 by phosphorylating MDM2 (Murine Double Minute 2) and affects cell growth [15]. The affected p53 adjusts gene expression involved in cell death with a transcription factor [16]. Therefore, caspase cascade is induced under the influence of the apoptosis intrinsic pathway, and apoptosis is induced through the activity of caspase-3 [17]. Therefore, in the present study, we sought to determine the expression of the anticancer activity mechanism in the AGS human gastric cancer cells, and whether or not the suppression of the proliferation of the protein would be caused by intrinsic apoptosis.

\section{Materials and Methods}

\section{Reagents}

Allium hookeri (AHE) were purchased from Heungdang company

*Corresponding author: Young-Min Kim, Department of Biological Sciences, College of Life Science and Nano Technology, Hannam University Yuseong-dero 1646, Yuseong-gu, Daejeon 305-811, South Korea, Tel: +82-42-629-8760; Fax: +82-42-629-8873; E-mail: kym@hnu.kr

Received July 11, 2018; Accepted August 06, 2018; Published August 08, 2018

Citation: Nam GH, Lee SJ, Kim YM, Kim GY, Jeon MJ, et al. (2018) The Extracts from Allium hookeri induces p53-independent Apoptosis through Mitochondrial Intrinsic Pathways in AGS Human Gastric Carcinoma Cells. J Cancer Sci Ther 10 198-204. doi: 10.4172/1948-5956.1000544

Copyright: (c) $2018 \mathrm{Nam} \mathrm{GH}$, et al. This is an open-access article distributed unde the terms of the Creative Commons Attribution License, which permits unrestricted use, distribution, and reproduction in any medium, provided the original author and source are credited. 
Citation: Nam GH, Lee SJ, Kim YM, Kim GY, Jeon MJ, et al. (2018) The Extracts from Allium hookeri induces p53-independent Apoptosis through Mitochondrial Intrinsic Pathways in AGS Human Gastric Carcinoma Cells. J Cancer Sci Ther 10: 198-204. doi: 10.4172/1948-5956.1000544

(Seoul, Korea). The AHE was refluxed with $95 \%$ ethanol for $24 \mathrm{hr}$. The extract was concentrated to remove the ethanol. The extract was dissolved in DMSO prior to treatment and refrigerated at $-18^{\circ} \mathrm{C}$. The Muse TM Annexin V apoptosis detection kit was obtained from Merck (Darmstadt, Germany). Specific antibodies that recognized mTOR, Akt, p53, Bax, Bak, procaspase-3, Bcl-2, and $\beta$-actin are obtained from Cell Signaling Technology (Beverly, USA). LY294002 (Akt inhibitor) and Rapamycin (mTOR inhibitor), Pifithrin- $\alpha$ (p53 inhibitor) was purchased from SIGMA (Spruce Street, St Louis, USA).

\section{Cell culture}

AGS Human Gastric Carcinoma Cells were obtained from the American Type Culture Collection (ATCC, USA). The cells were grown in RPMI-1640 medium (Hyclone, USA) containing $10 \%$ fetal bovine serum (Hyclone, USA) and $1 \%$ antibiotics $(100 \mathrm{mg} / \mathrm{L}$ streptomycin with $100 \mathrm{U} / \mathrm{mL}$ penicillin) in a $5 \% \mathrm{CO}_{2}$ at $37^{\circ} \mathrm{C}$. The cells were suspended by Trypsin-EDTA (Hyclone, USA) and separated at 1 $\times 10^{6}$ cells $/ \mathrm{mL}$ per plate, every $48-72$ hours.

\section{MTT assay}

Cells seeded on 96-well micro plates at 4000 cells/well were incubated with the test compounds for indicated time period. Respectively medium was removed and then incubated with $40 \mu \mathrm{l}$ of MTT solution ( $2 \mathrm{mg} / \mathrm{mL}$ MTT in PBS) for $1 \mathrm{~h}$. MTT is converted to a blue formazan. Absorbance was determined using an auto reader.

\section{Determination of apoptosis by Annexin V staining}

The cells were seeded at $1 \times 10^{6} \mathrm{cells} / \mathrm{mL}$ in plate and incubated for 24 $\mathrm{h}$. The cells were treated with the AHE for $24 \mathrm{~h}$ in a $5 \% \mathrm{CO}_{2}$ atmosphere at $37^{\circ} \mathrm{C}$. The inhibitor was pre-treated for 30-120 min before treating AHE. Total cells were harvested, collected by centrifugation, washed with PBS. Cells were stained with Annexin V for $20 \mathrm{~min}$. apoptosis was analyzed using a Muse TM Cell analyzer (Merck, Germany).

\section{Western blotting}

The cells were seeded at $1 \times 10^{6}$ cells $/ \mathrm{mL}$ plate. Then, the cells were treated with the AHE for $24 \mathrm{~h}$ in a $5 \% \mathrm{CO}_{2}$ atmosphere at $37^{\circ} \mathrm{C}$. The inhibitor was pre-treated for 30-120 min before treating AHE. The cells were scraped with RIPA lysis buffer. The primary antibody was then added following by overnight at $4^{\circ} \mathrm{C}$, following the addition of the secondary antibody was added following by $30-120 \mathrm{~min}$.

\section{Statistical analysis}

MTT assay was statistically analyzed using t-test (SPSS Inc.; Chicago, USA). A value of $\mathrm{P}<0.05$ was indicated to a statistically significant difference.

\section{Results}

\section{Impact of AHE on AGS human gastric cancer cell proliferation}

MMT assay after processing $\operatorname{AHE}(15,35,35,70,105,140$, and $170 \mu \mathrm{g} / \mathrm{mL}$ ) was applied to AGS human gastric cancer cells to confirm the effect of AHE on AGS and gastric cancer cell growth rate. The results show that, when the AHE was treated for 24 hours, the cell proliferation was suppressed in a dose-dependent manner (Figure 1A). The results of measuring the cytotoxicity of AHE to fibroblast cells of normal cells confirm that the proliferation rate of fibroblast cells was maintained at least 90\% (Figure 1B). When apoptosis was induced, the cells were broken up, the cells were condensed in chromatin, the bubbles formed in the plasma membrane, and the cells were divided into cells. Lamellipodia and philopodia, which play important roles in cell migration, were also lost and the cells lost adhesion. Therefore, we observed that such morphological changes in apoptosis and cell
A

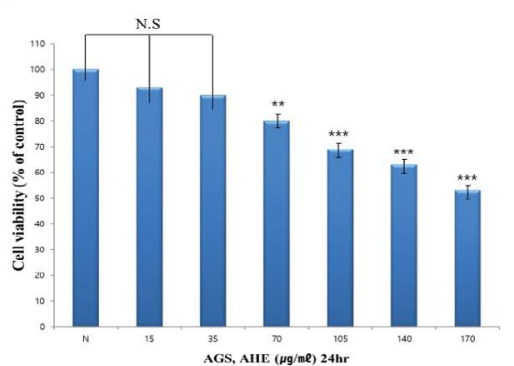

C

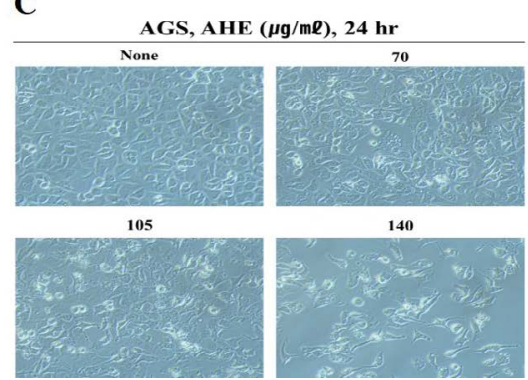

B

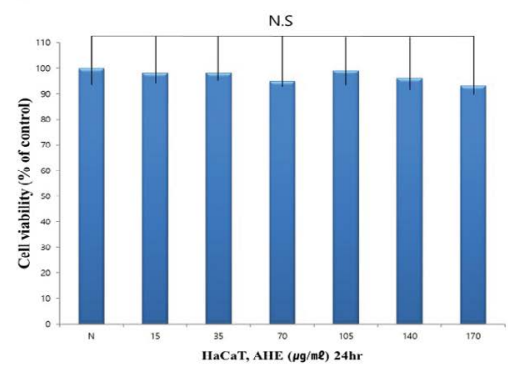

Figure 1: Cytotoxic and anti-proliferation Effects of AHE in AGS human gastric carcinoma cells (A) Cells were treated with variable concentrations of AHE (15 170 $\mu \mathrm{g} /$ $\mathrm{ml}$ ) for $24 \mathrm{hr}$. Cell viability was measured by MTT assay. The statistical analysis of the data was carried out by use of a t-test. ${ }^{*}$ means $p<0.05$, ${ }^{\star *}$ means $p<0.01$ and ${ }^{* \star *}$ means $+++p<0.001$ was compared to control. N.S. means not significant (each experiment, $\mathrm{n}=3$ ). (B) MTT assay evaluated cell viability. The statistical analysis of the data was carried out by use of a t-test. N.S. means not significant (each experiment, $n=3$ ). (C) Phase Contrast Image-Based Monitoring of Apoptosis Induction (X400 magnification, Axiovert 100, Zeiss, Germany). 
Citation: Nam GH, Lee SJ, Kim YM, Kim GY, Jeon MJ, et al. (2018) The Extracts from Allium hookeri induces p53-independent Apoptosis through Mitochondrial Intrinsic Pathways in AGS Human Gastric Carcinoma Cells. J Cancer Sci Ther 10: 198-204. doi: 10.4172/1948-5956.1000544

proliferation were inhibited when AHE was treated with AGS human gastric cancer cells. As a result, as shown in Figure 1C, we were able to see that the cells in the control group, which did not process anything, were relatively dense, uniform, and normally attached. It was confirmed that the higher the concentration of AHE, the lower the density of the cells, and the more cells become irregular [18].

\section{Determination of the Application of AGS human gastric cancer cells by AHE}

Early apoptosis occurs in the translocation of phosphatidylserine, an early sign of programmed cell death and the cell membrane remains undamaged in the process of translocation $[19,20]$. To distinguish whether the death of AGS stomach cancer cells under AHE processing is caused by apoptosis or necrosis, we measured the level of intracellular phosphatidylserine (PS) expression, which is considered to be the early stage of apoptosis development using Annexin V (Figure 2). As shown in Figure 1B, the ratio of Annexin V-positive cells was low in the control (5.9\%). However, as the concentration of AHE increased, the percent of annexin $\mathrm{V}$-positive cells increased as well: increasing the concentration of $23.17 \%(70 \mu \mathrm{g} / \mathrm{mL}), 26.20 \%(105 \mu \mathrm{g} / \mathrm{mL}), 31.90 \%(140$ $\mu \mathrm{g} / \mathrm{mL})$. Throughout this process, we observed that the treatment of AHE and the inhibition of the growth of AGS human gastric cancer cells were caused by apoptosis.

\section{Confirmation of apoptosis intrinsic pathway-related protein expression by AHE}

Mitochondria play an important role in apoptosis. Intrinsic pathway and Bcl-2 family of proteins also play an important role in maintaining its membrane potential [21]. Bcl-2 and Bcl-XL, which are anti-apoptotic proteins, are moved to maintain the stability of the mitochondria membrane and the pro-apoptotic proteins Bax and Bak move in the mitochondrial membrane to play a role of increasing membrane permeability. The caspase cade-inducing caspase- 3 is activated to decompose the PARP protein. Therefore, in the present study, Western blotting was performed in order to confirm the degree of expression of not only Akt, mTOR, and p53 proteins, which are the upstream regulators of apoptosis intrinsic pathway, but also affected downstream regulators. As shown in Figure 3, the reduction of p-Akt, p-mTOR and Bcl-2, Bcl-XL and pro caspase-3, which are anti-apoptotic proteins involved in cell proliferation, was confirmed. An increase in Bax, Bak, and cleaved-PARP of p53 and pro-apoptotic protein of the cancer suppressor gene was also confirmed. PARP, a protein decomposed by caspase-3, maintains the stability of DNA repair and genes. If a fragment is cut, it will lose its function. Therefore, it is possible to know that apoptosis by caspase activity is induced by the expression of the cleared-PARP [22,23]. In conclusion, we could learn that AHE induces apoptosis through an intrinsic pathway in AGS human gastric cancer cells.

\section{The effects of p53 and Akt and mTOR inhibitors on AGS human gastric cancer cells growth}

In order to confirm the relationship between AHE-induced cytotoxicity and apoptotic pathways, after the treatment of LY294002 (Akt inhibitor) or rapamycin (mTOR inhibitor), and the co-treatment of pifitrin- $\alpha$ (p53 inhibitor) by AHE were performed. We found that the AHE treatment group, as well as the LY294002 and the rapamycin treatment group showed a similar decrease as compared to the control. Moreover, the pifitrin- $\alpha$ treatment group did not show a significant difference with the control group. However, if pifitrin- $\alpha$ and AHE were co-treated, Despite the treatment of Pifitrin- $\alpha$, the number decreased in the same way as in the AHE treatment group (Figure 4). These results mean that AHE induces cytotoxicity and apoptosis through Akt, mTOR dephosphorylation, and p53 independent pathway downregulation.

\section{Confirmation of apoptosis effect and apoptosis intrinsic pathway-related protein expression by p53 and Akt and mTOR inhibitor}

In order to investigate the apoptosis effect of AGS human gastric cancer cells through intrinsic pathway, Anexin- $\mathrm{V}$ staining analysis was conducted using flow cytometry (Figure 5). Furthermore, as shown in Figure 6, we confirmed the control relation between the upstream regulators ( $\mathrm{p}$-Akt, $\mathrm{p}-\mathrm{mTOR}$ and $\mathrm{p} 53$ ) and downstream regulators
A

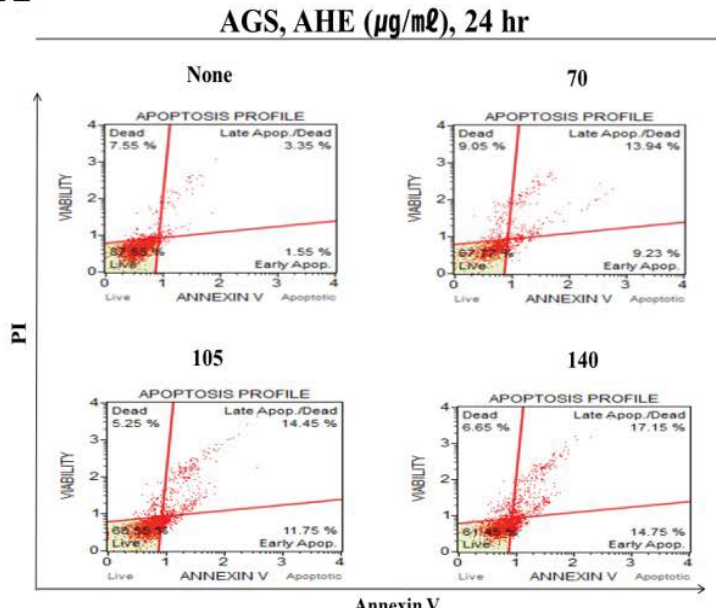

B

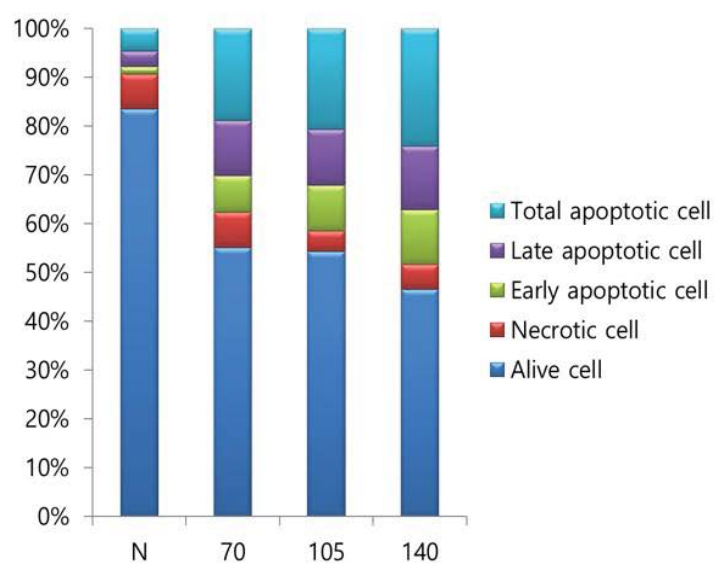

Figure 2: Apoptotic effects of different concentration AHE were evaluated by the Muse ${ }^{\mathrm{TM}}$ Annexin $\mathrm{V}$ and Dead Cell assay (A) Cell stained with Muse ${ }^{\mathrm{TM}}$ Annexin $\mathrm{V}$ and Dead Cell assay kit and analysed by Muse ${ }^{\mathrm{TM}}$ Cell Analyzer. Data show four cell population - Live, Dead, Early apoptosis and Late apoptosis. (B) Annexin $V$ staining was showed by five categories: live, necrosis, early apoptosis, late apoptosis and total apoptosis. AHE shown to induce apoptotic cell in the AGS cells mainly with the increased in total apoptotic cells and the apparent decreased in the live cells. AHE also significantly induced the total apoptotic cells in a dose-dependent manner. 
Citation: Nam GH, Lee SJ, Kim YM, Kim GY, Jeon MJ, et al. (2018) The Extracts from Allium hookeri induces p53-independent Apoptosis through Mitochondrial Intrinsic Pathways in AGS Human Gastric Carcinoma Cells. J Cancer Sci Ther 10: 198-204. doi: 10.4172/1948-5956.1000544
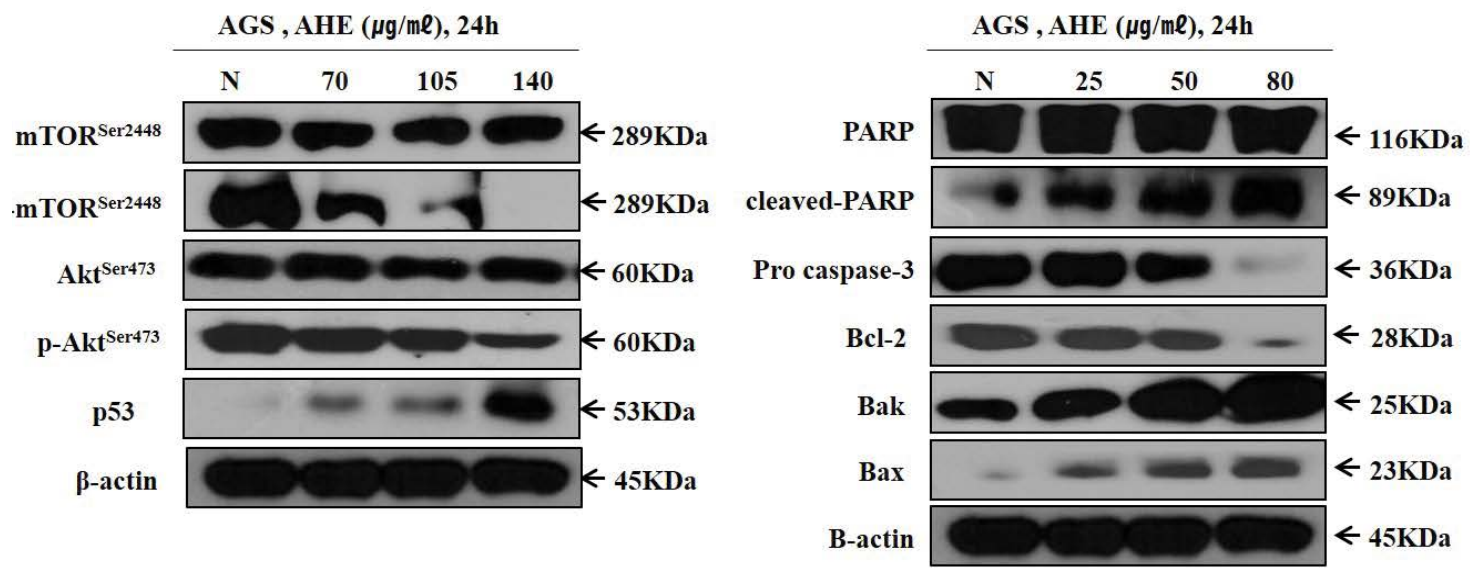

Figure 3: AHE regulates the expression of apoptotic and anti-apoptotic proteins. The expression of mTOR, cleaved PARP, Akt, p53, pro-caspase 3, Bcl-2, Bak, Bax and $\beta$-actin were analyzed by Western blot analysis.

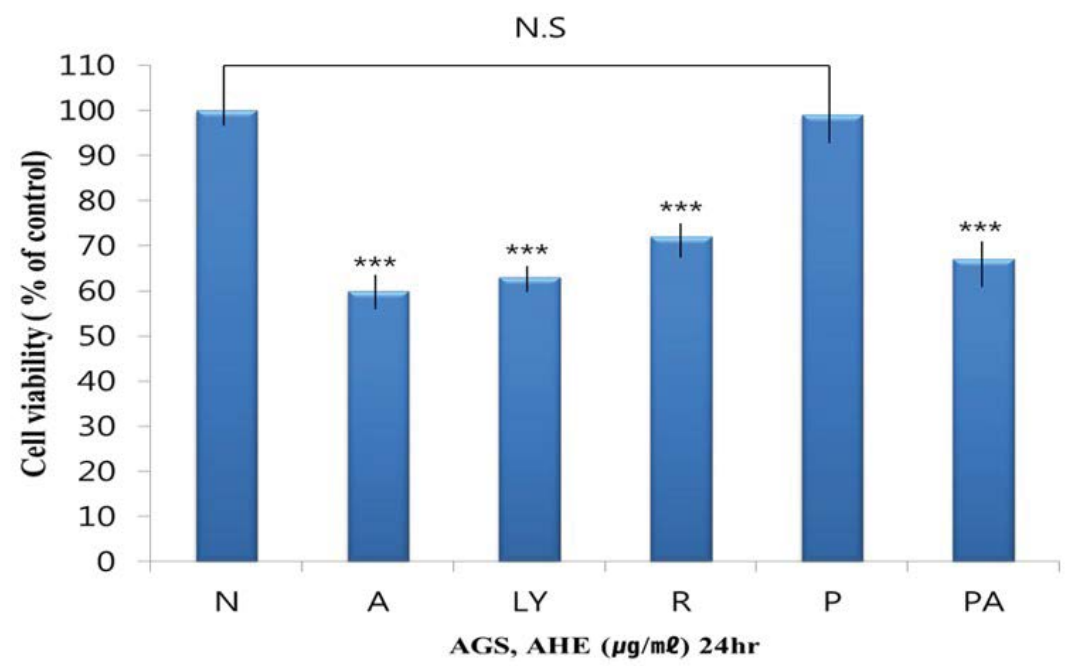

Figure 4: Effects on cell proliferation and the control of the signal proteins via inhibition of Akt, mTOR, p53. Cells were treated with $20 \mu \mathrm{M} \mathrm{LY294002} \mathrm{(Akt} \mathrm{inhibitor)}$ and 100nM Rapamycin (mTOR inhibitor), $20 \mu \mathrm{M}$ pifitrin- $\alpha$ (p53 inhibitor), AHE for 24h. (A) Cells viability was measured by MTT assay. The statistical analysis of the data was carried out by use of a t-test. * means $p<0.05,{ }^{* *}$ means $p<0.01$ and ${ }^{* * *}$ means $p<0.001$ compared to control. N.S. means not significant (each experiment, $n=3)$.

(Bcl-2, Bax, Bak, and pro caspase-3) by Western blot analysis after cotreatment or single-treatment with LY294002 and rapamycin, Pifitrin$\alpha$ and AHE. Similar to the MTT assay, the Anexin-V/ staining analysis results were verified by apoptosis. When AHE was single-treated, ca. 31.62\% apoptosis was induced, When LY294002 was single-treated, ca. $28.02 \%$ apoptosis was induced. Furthermore, when rapamycin and pifithrin- $\alpha$ were single-treated, ca. $23.36 \%$ and $3.28 \%$ of apoptosis was observed, respectively. Even though the p53 was decreased by pifithrin- $\alpha$, the group that co-treated pifithrin- $\alpha$ and AHE was similar to single-treated AHE. Based on the results of Western blotting, it was confirmed that the expression of p-Akt, p-mTOR and p53 proteins was reduced by the LY294002 and rapamycin and pifithrin- $\alpha$ treatments (Figure 6). Therefore, the expression of the pro-caspase-3, $\mathrm{Bcl}-2$ as the downstream regulators of the signal pathway was reduced, and the expression of the Bax, Bak, and cleaved PARP increased. When comparing the AHE treatment with apoptosis-related protein expression, we observed that the protein regulation of these apoptosis intrinsic pathway signaling paths that occurred was not different from when the LY294002 and rapamycin processing was performed. Previous studies have reported that the treatment of LY294002 and rapamycin affects the downstream regulators and induces apoptosis [24]. The pifithrin- $\alpha$ treating group decreased the expression of p53. Since the p53 does not affect Bax and Bak proteins whose activity increased, our results confirmed that AHE affects AGS human gastric cancer cells through the p53-independent pathway. As a result, apoptosis induced by AHE processing in the present study was controlled by the intrinsic pathway. This effect was confirmed to occur through the reduction of Akt and mTOR activity and the p53-independent pathway. Based on our results, it can be concluded that active ingredient analysis and various additional experiments should be conducted in the future to confirm the possibility of actual use of AHE as a therapeutic agent for stomach cancer. 
A

AGS, AHE ( $\mu \mathrm{g} / \mathrm{m \ell}), 24 \mathrm{hr}$

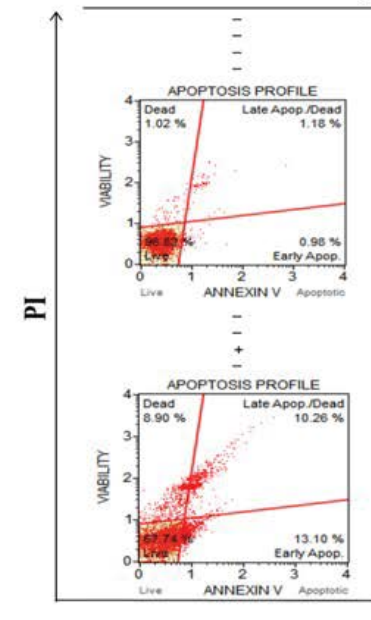

B

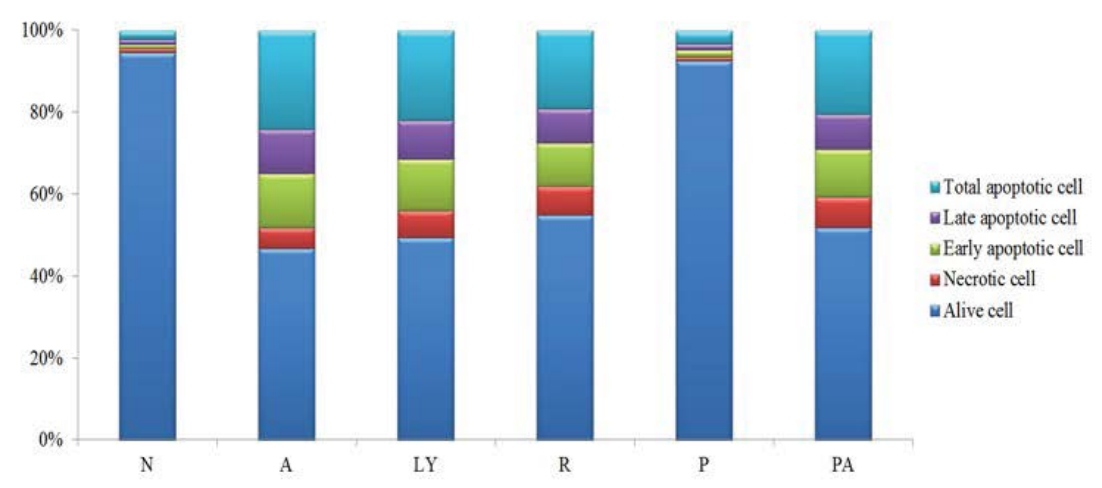

Figure 5: Apoptotic effects of different concentration $\mathrm{AHE}$ and signal protein inhibitor were evaluated by the Muse ${ }^{\mathrm{TM}}$ Annexin $\mathrm{V}$ and Dead Cell assay. (A) Apoptotic effects Cells treated LY294002(Akt inhibitor), Rapamycin (mTOR inhibitor), pifitrin- $\alpha$ (p53 inhibitor) and AHE were evaluated by the Muse ${ }^{\mathrm{TM}}$ Annexin V and Dead Cell assay. Data analyzed by flow cytometry (B) Annexin V staining was showed by five categories: live, necrosis, early apoptosis, late apoptosis and total apoptosis.

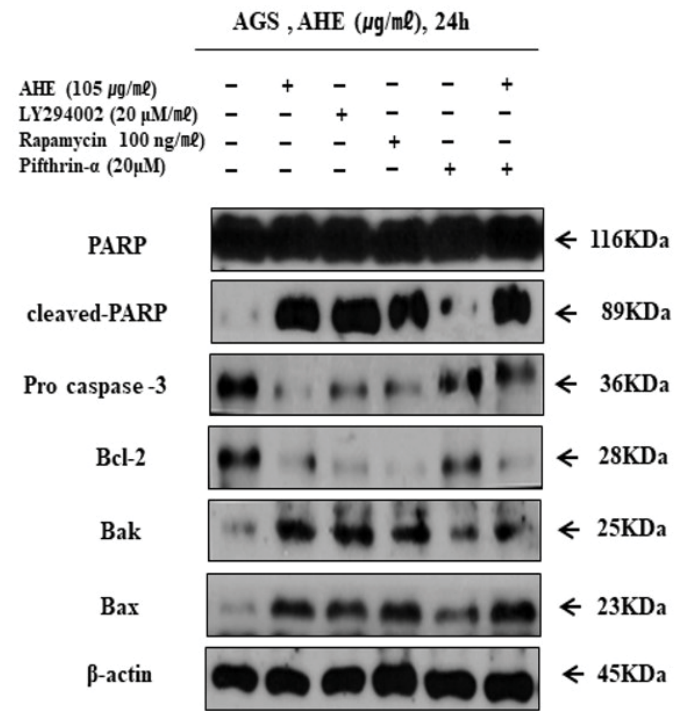

Figure 6: Protein level was indicated treated LY294002, Rapamycin, pifitrin- $\alpha$ and AHE. The expression of mTOR, cleaved PARP, AKT, p53, pro-caspase 3, Bcl-2, Bak, Bax and $\beta$-actin were analyzed by Western blot analysis. 
Citation: Nam GH, Lee SJ, Kim YM, Kim GY, Jeon MJ, et al. (2018) The Extracts from Allium hookeri induces p53-independent Apoptosis through Mitochondrial Intrinsic Pathways in AGS Human Gastric Carcinoma Cells. J Cancer Sci Ther 10: 198-204. doi: 10.4172/1948-5956.1000544

\section{Discussion and Conclusion}

Stomach cancer is the most common cancer worldwide, including Korea [25]. Therefore, treatment methods that induce apoptosis are urgently needed to treat stomach cancer. In the present study, we investigated the apoptosis effect of extract from Allium hookeri, a plant species that proved to be effective in cancer treatment in the previous literature [26]. Akt signaling pathway is frequently activated in cancers including glioblastoma multiforme (GBM), Ras signaling pathway where this kinase network regulates survival $[27,28]$. We showed that AHE induces apoptosis by inhibiting Akt signaling pathway. Akt(serine/ threonine kinase) mediates of PI3K-initiated signaling pathway by phosphorylating and inhibiting death-inducing proteins and blocks phosphorylates mTOR, MDM2 [29,30]. Phosphorylated-mTOR has emerged as a major regulator of cell proliferation and protein synthesis $[31,32]$. Previous studies have shown that natural substances inhibit Akt, mTOR induce apoptosis through the intrinsic pathway [33,34]. Furthermore, Phosphorylated-MDM2 inhibits the transcriptional activity of p53 and more importantly, promotes its apoptosis by intrinsic pathway $[30,35,36]$ we confirmed that AHE can induce apoptosis through its downregulation of Akt and mTOR whereby proteins associated with intrinsic pathway work by p53-independent pathway [37]. First, we demonstrated the cytotoxicity effect of AHE through the MTT assay. As a result, AHE significantly reduced viability of cells in the dose-dependent manner. In addition, we detected apoptotic cells using Annexin V staining and found that treatment of AHE on AGS human gastric cancer cells changes the number of apoptotic cells in the dose-dependent manner. Furthermore, in order to investigate if apoptosis goes through the intrinsic pathway, we used Western blotting to confirm the degree of expression of not only Akt, mTOR, and p53 proteins, which are the upstream regulators of apoptosis, Intrinsic pathway, but also affected downstream regulators $[38,39]$. Then, we were able to observe that the reduction of $\mathrm{p}$-Akt, $\mathrm{p}$-mTOR and $\mathrm{Bcl}-2, \mathrm{Bcl}-\mathrm{XL}$ and pro caspase- 3 , which are anti-apoptotic proteins involved in cell proliferation. An increase in Bax, Bak, and cleavedPARP of p53 and pro-apoptotic protein of the cancer suppressor gene were also confirmed. Additionally, to confirm the effect of Akt and mTOR and p53 in AHE-induced apoptosis, we induced Akt, mTOR and p53 inhibitors. The LY294002 treated group, rapamycin-treated group, and AHE single-treated group were induced in similar number of cell toxicity and apoptosis. Even when co-treated with AHE and pifithrin- $\alpha$, the groups had reduced apoptosis (pifithrin- $\alpha$ blocks the expression of p53 and reduces apoptosis [40]). It was not inhibited and apoptosis was normally induced. These results mean that AHE induces cytotoxicity and apoptosis through Akt, mTOR dephosphorylation, and p53-independent pathway downregulation.

\section{Acknowledgements}

The study was supported by the 2018 Forbio Ltd. Research Fund.

\section{References}

1. Hye-In K, Jae-Yong K, Hyun-Dong C, Kyung-Wuk P, Jum-Soon K, et al. (2010) Resveratrol induces apoptosis in primary human prostate cancer cells. Korean J Food \& Nutr 39: 1119-1125.

2. Siegel RL, Miller KD, Jemal A (2017) Cancer statistics, 2017. CA Cancer J Clin 67: 7-30.

3. Oh C, Won $\mathrm{Y}$, Jung $\mathrm{K}$, Kong $\mathrm{H}$, Cho $\mathrm{H}$, et al. (2016) Cancer Statistics in Korea: Incidence, mortality, survival, and prevalence in 2013. Cancer Research and Treatment 48: 436-450.

4. Jeong Hye K (2012) Influencing factors on depression in stomach cancer patients receiving chemotherapy. Korean J Adult Nurs 24: 588-596.
5. Kim YA, Lee JI, Kim HJ, Kong CS, Nam TJ, et al. (2009) Antiproliferative effect of extracts, fractions and compound from Vitex Rotundifolia on human cancer cells. J Appl Biol Chem 52: 180-186

6. Jeong-Seung H, Bong Han L, Xiangxue A, Ha Ram J, Young-Eun K, et al. (2015) Total phenolics, total flavonoids, and antioxidant capacity in the leaves, bulbs, and roots of Allium hookeri. Korean J Food Sci Tech 47: 261-266.

7. Amabile N, Susini G, Pettenati-Soubayroux I, Bonello L, Gil JM, et al. (2008) Severity of periodontal disease correlates to inflammatory systemic status and independently predicts the presence and angiographic extent of stable coronary artery disease. J Intern Med 263: 644-652.

8. Park C, Jin CY, Choi TH, Hong SH, Choi YH (2013) Effect of proapoptotic Bcl-2 on naringenin-induced apoptosis in human leukemia U937 cells. J Life Sci 23 1118-1125.

9. Zhu D, Lin Z, Li Z (2015) Aqueous extract of Huang-lian induces apoptosis in lung cancer cells via P53-mediated mitochondrial apoptosis. Braz arch biol technol 58: 353-357.

10. Park SY, Lee SH, Park OJ, Kim YM (2011) Apoptotic effects of curcumin and EGCG via Akt-p53 signaling pathway in HCT116 colon cancer cells. J Life Sci 21: 89-95.

11. Lee SH, Kim IS, Park SY, Park OJ, Kim YM (2011) Quercetin induces apoptosis via regulation of mTOR-VASP signaling pathway in HT-29 colon cancer cells. Cancer Prevention Research16: 340-347.

12. Ogawara Y, Kishishita S, Obata T, Isazawa Y, Suzuki T, et al. (2002) Akt enhances Mdm2-mediated ubiquitination and degradation of p53. J Biol Chem 277: 21843-21850.

13. Jung CR, Lim JH, Choi Y, Kim DG, Kang KJ, et al. (2010) Enigma negatively regulates p53 through MDM2 and promotes tumor cell survival in mice. J Clin Invest 120: 4493-4506.

14. Kitagishi Y, Kobayashi M, Kikuta K, Matsuda S (2012) Roles of PI3K/AKT/ GSK3/mTOR pathway in cell signaling of mental illnesses. Depress Res Treat.

15. Jeong YJ, Kang KJ (2011) Effect of Angelica keiskei extract on apoptosis of MDA-MB-231 human breast cancer cells. Korean J Food \& Nutr 40: 1654-1661.

16. Bae GC, Bae DY (2012) The anti-inflammatory effects of ethanol extract of Allium hookeri cultivated in South Korea. Korean J Herbol 27: 55-61.

17. Kim EJ, Park HS, Lim SS, Kim JS, Shin HK, et al. (2008) Effect of the hexane extract of Saussurea lappa on the growth of HT-29 human colon cancer cells. Korean J Food Sci Tech 40: 207-214.

18. Gap-Soon Y, Jin-Moo L, Chang-Hoon L, Jun-Bock J, Kyung-Sub L (2011) Study of apoptosis by scirpi tuber in Hela cell and MCF-7 cell. J Korean Obstet Gynecol 24: 1-13.

19. Lee HS, Koo YC, Lee KW (2009) Suppressive activity of extract of Termialia chebula Retz. on hepatic fibrosis. Korean J Food Sci Tech 41: 597-601.

20. Yonekawa T, Thorburn A (2013) Autophagy and cell death. Essays Biochem 55: 105-117.

21. Bae OS, Yoo YM, Lee SG (2006) Pro-apoptotic effect of mori cortex radicis in A549 lung cancer cells. Report of ICTM Proposal 112-112.

22. Duriez PJ, Shah GM (1997) Cleavage of poly (ADP-ribose) polymerase: A sensitive parameter to study cell death. Biochem Cell Biol 75: 337-349.

23. Lim EG, Kim GT, Kim BM, Kim EJ, Ha SH, et al. (2016) Apoptotic effects and cell cycle arrest effects of extracts from Cnidium monnieri (L.) Cusson through regulating $A k t / m T O R / G S K-3 \beta$ signaling pathways in HCT116 colon cancer cells. J Life Sci 26: 663-672.

24. Lee SH, Kim GT, Kim JI, Lim EG, Kim IS, et al. (2013) The Extract from Lysimachia foenum-graecum induces apoptosis in MCF-7 breast cancer cells. KSBB Journal 28: 303-309.

25. Park JY, Yoon KY (2014) Comparison of the nutrient composition and quality of the root of Allium hookeri grown in Korea and Myanmar. Korean J Food Sci Tech 46: 544-548.

26. Fan QW, Weiss WA (2011) Autophagy and Akt promote survival in glioma Autophagy 7: 536-538.

27. Pap M, Cooper GM (1998) Role of glycogen synthase kinase-3 in the phosphatidylinositol 3-kinase/Akt cell survival pathway. J Biol Chem 273 19929-19932 
Citation: Nam GH, Lee SJ, Kim YM, Kim GY, Jeon MJ, et al. (2018) The Extracts from Allium hookeri induces p53-independent Apoptosis through Mitochondrial Intrinsic Pathways in AGS Human Gastric Carcinoma Cells. J Cancer Sci Ther 10: 198-204. doi: 10.4172/1948-5956.1000544

28. Franke TF, Hornik CP, Segev L, Shostak GA, Sugimoto C (2003) PI3K/Akt and apoptosis: Size matters. Oncogene 22: 8983-8998.

29. Hay N, Sonenberg N (2004) Upstream and downstream of mTOR. Genes Dev 18: $1926-1945$.

30. Laplante M, Sabatini DM (2012) mTOR signaling in growth control and disease. Cell 149: 274-293.

31. Daniele S, Costa B, Zappelli E, Da Pozzo E, Sestito S, et al. (2015) Combined inhibition of AKT/mTOR and MDM2 enhances glioblastoma multiforme cell apoptosis and differentiation of cancer stem cells. Scientific reports 5: 9956.

32. Kim EJ, Kim GT, Kim BM, Lim EG, Kim SY, et al. (2017) Apoptosis-induced effects of extract from Artemisia annua Linné by modulating PTEN/p53/PDK1/ Akt/signal pathways through PTEN/p53-independent manner in HCT116 colon cancer cells. BMC Complement Altern Med 17: 236.

33. Haupt S, Berger M, Goldberg Z, Haupt Y (2003) Apoptosis-the p53 network. J Cell Sci 116: 4077-4085.
34. Moll UM, Petrenko O (2003) The MDM2-p53 interaction. Mol Cancer Res 1: 1001-1008.

35. Schuler M, Green DR (2001) Mechanisms of p53-dependent apoptosis. Biochem Soc Trans 29: 684-688.

36. Feng Z, Zhang $\mathrm{H}$, Levine AJ, Jin S (2005) The coordinate regulation of the p53 and mTOR pathways in cell. Proc Natl Acad Sci USA 102: 8204-8209.

37. Downward J (2004) PI 3-kinase, Akt and cell survival. Semin Cell Dev Biol 15 177-182.

38. Elmore S (2007) Apoptosis: A review of programmed cell death. Toxicol Pathol 35: $495-516$

39. Rocha S, Campbell KJ, Roche KC, Perkins ND (2003) The p53-inhibitor pifithrin- $\alpha$ inhibits firefly luciferase activity in vivo and in vitro. BMC Mol Biol 4: 9

40. Leker RR, Aharonowiz M, Greig NH, Ovadia H (2004) The role of p53-induced apoptosis in cerebral ischemia: effects of the p53 inhibitor pifithrin $\alpha$. Exp Neurol 187: 478-486. 